\title{
A Confirmatory Investigation of the Factors Influencing the Cloud Adoption in Local Government Organisations in Australia.
}

\author{
Prasanna Balasooriya L.N. \\ School of Engineering and Technology \\ Central Queensland University \\ Melbourne, Australia \\ Email: p.balasooriya@cqu.edu.au
}

\begin{abstract}
The purpose of this paper is to discuss major factors of two well-known theoretical frameworks namely Technology-Organization-Environment (TOE) and Technology Acceptance Model (TAM), and examine how those factors could influence the Organizational decision on Cloud technology adoption. The research underlining was carried out using quantitative research methodology based on a survey questionnaire distributed to IT professionals across Australia. The survey questionnaire was developed based on 12 hypotheses and 24 indicator variables. Around 200 responses were analysed by using twotier approach (a) confirmatory factor analysis to confirm the reliability and validity of the latent variables, and (b) analysis of the structural model to confirm or reject the hypothesis. The final analysis of the results has revealed that only 8 hypotheses are significant and can be adopted. Furthermore, results have revealed that 4 hypotheses have a non-significant impact on the proposed framework and can be rejected from the framework.
\end{abstract}

Keywords Cloud adoption, Cloud technology, integrated framework, technology acceptance, structural equation modelling, SmartPLS 


\section{Introduction}

Cloud technology is one of the innovations that deliver information technology services in modern world. This technology has an immense potential for improving Organizational service delivery and performance at a higher rate of the Cloud adoption (Abduljalil and Zainuddin 2015). The National Institute of Standards and Technology (NIST) defines Cloud technology as a model for enabling convenient, on-demand network access to a shared pool of configurable computing resources. Hence, this includes networks, servers, storage, applications, and services that can be rapidly provisioned and released with minimal management effort or service provider interaction (Alijani et al. 2014).

Organizations around the world recognize Cloud technology as an emerging technology available in the information technology domain at current. This is due to its capabilities to assist organizations in reducing their overall expenditure through improvement in their services. In addition, the use of Cloud technology increases the collaboration across the organization and the scalability acceptance up to an exceptional level (Balasooriya et al. 2016). The Cloud computing technology is an emerging technology that can be used to improve the way that organizations conduct their business. Cloud computing technology has capabilities to (a) reduce cost (b) improve performance (c) reduce maintenance (d) better storage, and (e) increased security (Maresova et a. 2017) which could certainly support organizations to transform their business operations to the Cloud. However, despite the emerging benefits of Cloud technology, Australian organisations are still far behind than the other countries in the world. Therefore, AlKharusi and Al-Badi (2016) found that the organizations who do not have prior experience and knowledge showed a negative attitude towards adopting this technology. Raza et al. (2015) explained that controversial view of the fear of job losses in the minds of the workforce is one of the major factors that have contributed slow growth of Cloud computing. Willcocks et al. (2013) believes that the adoption of Cloud technology beyond its IT operational benefits could be problematic and slow the adoption, and infrastructure failures could have contributed negatively to rethink about the decision to adopt this technology.

A significant number of empirical studies were found for Cloud adoption in general, but most of those studies were focused on general benefits and risks of Cloud adoption. Thus, there are limited academic focus on the Cloud Adoption in Local Government in Australia. Therefore, the focus of this paper is to integrate two well know theoretical frameworks, TOE and TAM frameworks together to study their impact on the Cloud adoption in Local Government environment Australia.

The paper is organised as follow: first we provide a comprehensive review of TOE and TAM models. We then present the conceptual research model with comprehensive review of factors with each model, which will provide the theoretical foundations for the research model and then propose the hypotheses. Thereafter, we discuss the research methodology and the results in details. Then we conclude the paper with summary of our contribution and discussion on the limitation of the research.

\section{Review of the Research Framework}

\subsection{Technology, Organization, and Environment framework (TOE)}

The TOE has been recognized as one of the organizational level theories that could help to describe its key elements: technology, organization and environment. The technology element will describe the internal and external technological context which is related to the organization. The organization element will describe the organizational context such as organizational size, scope, managerial structure and internal resources of the organization. Lastly, the environmental element will assist to identify the environmental area where organization conducts its business, its industry and technology dealings with the government. Therefore, TOE framework could be used to examine the influence of technological context (perceived benefits and costs), organizational context (organizational size, management support etc.) and environment context (trading partners, competitive advantages) on adoption of Cloud computing technology (Hsin-Pin and Hsiang-Ting 2014)

\subsection{Technology Acceptance Model (TAM)}

Organizations will be investing so much in information technology systems and projects for so many reasons such as cutting costs, reducing their pressure and improving the quality of services and products that they offer. Technology acceptance model (TAM) is one of the models that has been developed to predict the systems use (Legris et al. 2003). The TAM model has two key beliefs about a new technology, Perceived usefulness (PU) and Perceived ease of use (PEOU), determine a person's to adopt a new technology. Users acceptance of new technology depends primarily on its functions (PU) and secondarily 
on the ease or difficulty with which its functions can be performed (PEOU). The perceived usefulness (PU) and user attitude towards usage (A) may influence the behavioural intentions (BI) of the user to use the new technology that has been adopted (FĂDor 2014). The predictive power and parsimony of TAM enables researchers to apply it to various settings and analyse and understand different user behaviours (Ashraf et al. 2014). Therefore, TAM is a useful theoretical framework that could be applied to understand and explain why users will accept or reject new technology (Legris et al. 2003).

\section{Conceptual Research Model}

Hsin-Pin and Hsiang-Ting (2014) and Lin (2014) have found that the TOE framework can only be used to categorize its variables and does not represent an integrated conceptual framework or will not produce a well-developed theory. Legris et al. (2003), FĂDor (2014), Wu and Chen (2017) and Ashraf et al. (2014) revealed that TAM will only be measuring the perceived adoption on the future behaviour of the adoption rather than measuring the actual behaviour of the adoption. Wu and Chen [25] further mentioned that TAM cannot be used to handle new technological solutions or services due its restricted constructs within the model. Thus, Ashraf et al. (2014) has concluded that due to the limitations that have been found, TAM framework could not provide consistent results of the measured variables. Ashraf et al. (2014) has suggested extending the initial scope of TAM model to include other factors which could be important in technology acceptance.

In this research, a following conceptual research framework (as illustrated in Figure 1) has been developed by combining the TOE and TAM frameworks. However, to limit the scope of this paper, the author has used only technology context of TOE with PU \& PEOU of TAM model to investigate how factors could influence the technology acceptance and adoption of Cloud technology.

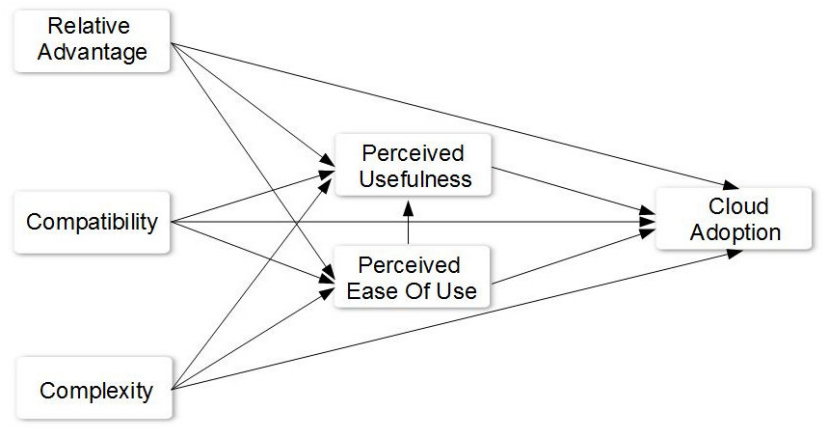

Figure 1: Proposed conceptual model

It has been found that Relative Advantage (RA), Compatibility (COMP) and Complexity (CLX) are major contributing factors of Technological context in the TOE. Furthermore, the literature has been revealed that PU (Perceived Usefulness) and Perceived Ease of Use (PEOU) are two main factors in TAM which could influence adoption intentions of Cloud technology. Thus, proposed model will extend the initial scope of both model and will eliminate some of the limitations that have been discussed in this paper. Most importantly, integration of major constructs of both frameworks in the proposed model will provide a more accurate view of the technology adoption.

\subsection{Relative Advantage}

Rogers (2010) explained relative advantage as the degree to which an innovation is perceived as being better than the idea it supersedes. Thus, it is a reasonable expectation for organizations to take into considerations of the advantages stem from adopting it (Wang et al. 2010). Hence, the adoption of Cloud computing technology could be seen as an adopting innovation to the organization. In particular, adopting innovative technologies such as Cloud computing technology could bring the benefits that are associated with it and offer economical and political legitimacy (Wang et al. 2016) to the adoption. However, further analysis has revealed that tangible and intangible benefits such as increase of revenue, reduction of operational cost, increase of productivity, increase of efficiency of work processes, response time improvement, increased cash flow, competitive advantage, improved customer service, better relations with business partners and other opportunities are some of the major elements of relative advantage (Hameed and Counsell 2014, Premkumar et al. 1994). Thus, the relative advantage has a none-arguable significant influence on the decision of adoption of Cloud computing (Hung et al. 2010). As per previous findings, the researcher believes that adoption of Cloud computing technology could bring some valuable benefits such as reduced operating costs, improved response time, improved 
productivity and provide a greater competitive advantage to the organization. Therefore, many studies suggested that relative advantage or perceived benefits as one of the top influencing factors to be considered to examine the Cloud adoption, and it could positively affect the Cloud adoption (Hameed and Counsell 2014).

\subsection{Compatibility}

Compatibility has been described as the degree to which an innovation is perceived as consistent with the needs, existing values, past experience and technological infrastructure of the adopter (Rogers 2010) . If new technology is more compatible with the existing business process and systems, the less resistance will occur during the adoption process (Premkumar et al. 1994). Thus, resistance to the new technology has negative effects on the usage of the new technology. Thus, it could impact the adoption, and adopters most likely reject its adoption (Hameed and Counsell 2014). However, Tornatzky (2005) suggested that compatibility factor could positively impact the Cloud adoption in an organization.

\subsection{Complexity}

Complexity in new technology adoption can be seen as the degree to which an innovation is perceived as relatively difficult to understand and use (Rogers 2010, Haimes et al. 2015). Thus, complexity factor could distance the Cloud adaptors from adopting Cloud technology for their organizations, and it could have a negative impact on technology adoption decisions (Hameed and Counsell 2014). Tornatzky (2005) suggested that complex technologies could not be adopted successfully and thereby it could not bring the expected efficiency to the organization. Also, complexity factors expected to influence Cloud adoption decisions negatively, and people may not have confidence in the technology because it is relatively new to them (Hsin-Pin et al. 2014, Willcocks 2013).

\subsection{Perceived Usefulness (PU)}

Perceived Usefulness (PU) has been defined as the degree to which a person believes that using a particular system would enhance his performance at work (Ratten 2015, Balasooriya et al. 2017). Thus, usefulness can be seen as user's perception of the benefits of using a technology or technological services. Also, the usefulness may impact user's lifestyle and the way that they do work. The users who believe that the new technology leads them to have good results will see it as useful (Balasooriya et al. 2017, Awa et al. 2015). PU is one of the most powerful diagnostic lenses that can be used to see how to use and intentions to use are influenced. A PU is one of the most powerful indicators that can be used in technology acceptance to measure user behaviour (Balasooriya et al. 2017, Awa et al. 2015). Furthermore, PU can be seen as a positive influential factor in Cloud adoption (Balasooriya et al. 2017, Armitage and Conner 2001).

\subsection{Perceived Ease of Use (PEOU)}

PEOU is the degree to which a person believes that using a particular system would be free of effort (Balasooriya et al. 2017, Balasooriya et al. 2016). This element has been defined to measure the prospective users' assessment of the mental effort required for the use of target application (Balasooriya et al. 2017, Awa et al. 2015). Thus, this element will explain user's perception of how it is easy to use a new technology that they were willing to accept. Users always evaluate and accept the technology based on what kind skills, information and experiences are required to use the technology. Therefore, this indicator will predict the users' inner-feeling about the technology acceptance (Ratten 2015, Balasooriya et al. 2017). Thus, PEOU can contribute positively to influence PU.

\subsection{Adoption (Al)}

Sintonen and Immonen (2013) and Balasooriya et al. (2017) argued that user willingness to adopt modern technology can be measured by analysing the market due to individual's behavioural intention to adopt or start new services. Therefore, individual organizations are often needed act and incorporate new technologies into their organization to improve their business processes to be competitive to survive in the rapidly changing market. Furthermore, Balasooriya et al. (2017) and Tsai \& Hsu (2012) stated that organizational readiness is used as an element to measure the capabilities of an organization for adopting common systems, where organizational readiness positively associated with the adoption.

As illustrated in Figure 2, twelve hypotheses were developed based on the above discussion. Furthermore, Figure 3 illustrate the visual representation of the hypothesis in the proposed model. 


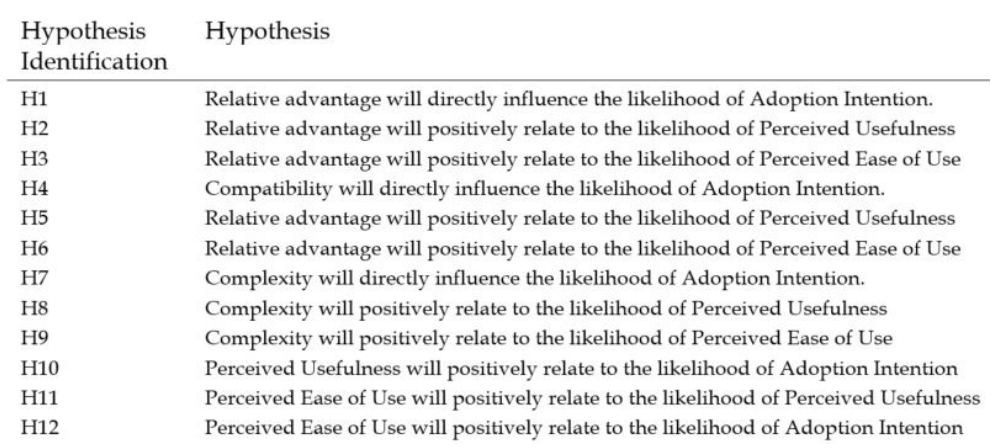

Figure 2: List of hypotheses

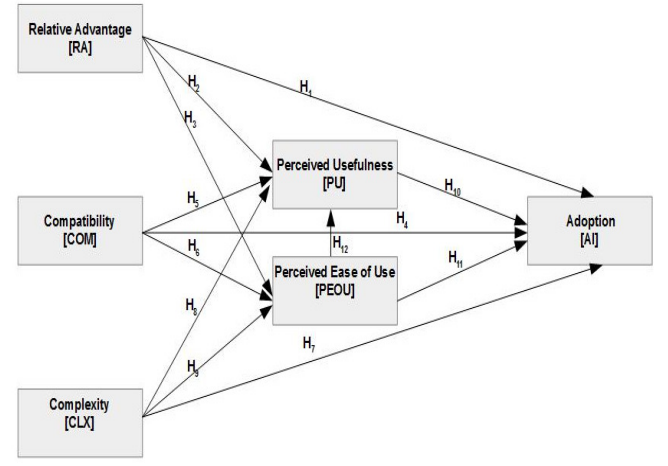

Figure 3: Visual representation of hypothesized relationships of the model

\section{Research Background and methodology}

\subsection{Research Background}

To evaluate the proposed conceptual framework illustrated in Figure 1 above, a well-designed survey questionnaire was distributed to information technology professionals across all Local government organisations in Victoria via Survey Monkey. Twenty eight individual variables have been used in this survey to gain a deeper knowledge of how technological factors of TOE and PU and PEOU of TAM could affect the adoption intention of Cloud technology.

The sample that has been used in this study represent the general population of professionals who are currently employed and located in different geographical locations across Australia. At the end of the data collection phase, 210 responses were collected and analysed for the statistical validity of the data. Therefore, it has been found that only $92 \%$ of the data is statistically valid and can be used for further analysis. Eight percent of incomplete or invalid data has been removed from the dataset.

\subsection{Research Methodology}

As Isma'ili et al. (2016) explained, Partial Least Squares - Structural Equation Modelling (PLS-SEM) is a multivariate method that could be used to identify the correlative relationships between multiple variables. The concepts that are not directly measured will be operationalized by compositing factor analysis, and path analysis can be used to expose the relationships between each concept. Furthermore, Völckner et al. (2010) strengthen Ismaill's argument by explaining that PLS-SEM is the most suiFi approach for researchers when their proposed model is complex. He further explained that PLS-SEM does not lead to a non-convergent result in the complex modelling environment and it is particularity appropriate to produce better results.

Isma'ili et al. (2016) and Balasooriya et al. (2017) further pointed out that PLS-SEM approach has a major advantage over other multivariate modelling techniques because PLS-SEM is s non-parametric method. Thus, PLS-SEM approach mainly helps researchers to (a) visualize the relationships exist between the indicator and latent variables, and (b) explore where organizations need to allocate more resources. Therefore, PLS-SEM has been chosen as an appropriate modelling technique for this study. 


\subsection{Results and Discussion}

Based on the literature review, the following model has been used for this study as illustrated in Figure 4. Therefore, a factor loading coefficients indicate the strength and the direction of

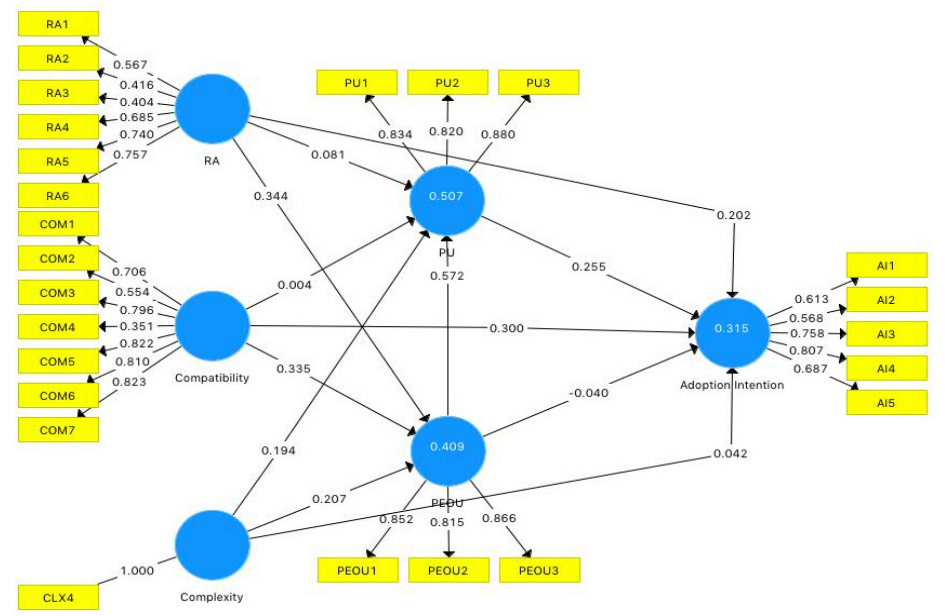

correlation between the indicator and latent variables. The relationship between each latent variable represents the structural model, which has been measured with PLS path coefficients.

Figure 4: Conceptual model with factor loadings

As described by Anderson \& Gerbing (1998), the two-tier approach has been adopted in this research study to overcome the issues in single-tier approach. Therefore, Internal consistency, internal reliability, convergent validity, and discriminant validity of the model will be examined within confirmatory factor analysis. Furthermore, the coefficient of determination (R2), Predictive relevance (q2), size and significance of paths coefficient, f2 effect size and q2 effect size will be examined within the analysis of structural equation model.

\subsubsection{Approach 1 - Confirmatory factor analysis}

The composite reliability varies between $\mathrm{o}$ and 1 , which higher values indicate the higher level of reliability and lower values indicate the lower level of reliability. As suggested by Hair et al. (2014), composite reliability value of 0.50 will an acceptable threshold value to evaluate the internal consistency reliability. Hair et al. (2014) further added that composite reliability values below the standard threshold of 0.50 will indicate a lack of internal consistency reliability of the model.

The coefficients of determination (R2) of Perceived Usefulness (PU) is 0.50, Perceived Ease of Use (PEOU) is 0.40 and Adoption intention (AI) is 0.30 . Thus, this explains that relative advantage (RA), compatibility (COM), and Complexity (CLX) explain $50 \%$ of the variance of PU and $40 \%$ of the variance of PEOU.

Furthermore, RA, COM, CLX, PU and PEOU explain 30\% variance of adoption intention (AI). Figure 5 illustrates the values of coefficients determination (R2) of the proposed model.

\begin{tabular}{lcc}
\multicolumn{3}{c}{ Values of coefficients determination $\left(\mathrm{R}^{2}\right)$} \\
\hline & R Square & R Square Adjusted \\
\hline PU & 0.51 & 0.50 \\
PEOU & 0.41 & 0.40 \\
AI & 0.32 & 0.30
\end{tabular}

Figure 5: Values of coefficients determination $\left(R^{2}\right)$

The values of inner-model suggest that PEOU has the strongest effects on PU (0.572), followed by RA $>$ PEOU 0.344, COM->PEOU 0.335, COM->AI 0.300, PU->AI 0.225, CLX->PEOU 0.207, RA->AI 0.202 and CLX-PU 0.194. Furthermore, RA and COM have similar effects (0.34) on PEOU. Therefore, it suggests that hypothesized path relationships of $\mathrm{H}_{12}, \mathrm{H}_{3}, \mathrm{H} 6, \mathrm{H}_{4}, \mathrm{H} 1 \mathrm{O}, \mathrm{H} 9, \mathrm{H} 1, \mathrm{H} 8$ have exceeded its standardized path coefficient threshold of 0.10 , and are statistically significant. However, the hypothesised relationship between perceived ease of use (PEOU) and adoption intention (AI) has reported a strong negative effect. Furthermore, the relationship between RA->PU, CLX->AI, and COM$>$ PU have reported weaker relationship, and are under its standardized path coefficient threshold value 
of 0.10 . Therefore, the test has confirmed that $\mathrm{H}_{2}, \mathrm{H}_{7}, \mathrm{H}_{5}$ and $\mathrm{H}_{11}$ are statistically non-significant in the proposed model.

As Isma'ili et al. (2016) concluded, it is an essential procedure to determine the reliability and validity of the latent variables to complete the examination of the model. Thus, it is important to examine the values of indicator reliability, composite reliability and average variance extracted in the proposed model. As illustrated in Table 1, indicators loadings of each indicator have reported positive values, which are greater than the minimum acceptable threshold value of 0.4 , and all of them are closer to the preferred level 0.70. Therefore, this has concluded that all the indicators have a positive impact on the model.

\begin{tabular}{|c|c|c|c|}
\hline $\begin{array}{c}\text { Latent } \\
\text { Variables }\end{array}$ & $\begin{array}{c}\text { Composite } \\
\text { Reliability }\end{array}$ & $\begin{array}{c}\text { Average } \\
\text { Variance } \\
\text { Extract (AVE) }\end{array}$ & $\begin{array}{c}\text { Adjusted } \\
\text { AVE }\end{array}$ \\
\hline RA & 0.770 & 0.370 & 0.4 \\
\hline COM & 0.870 & 0.510 & 0.5 \\
\hline CLX & 1.000 & 1.000 & 1.0 \\
\hline PU & 0.880 & 0.710 & 0.7 \\
\hline PEOU & 0.880 & 0.710 & .07 \\
\hline AI & 0.820 & 0.480 & 0.5 \\
\hline
\end{tabular}

Table 1: Summary of the composite reliability and average variance extracted

The composite reliability has been used to find the internal consistency reliability of the model (Hair et al. 2011). As illustrated in Table 1 , the composite reliability values presented are greater than its standard threshold value of o.6. therefore, this result has confirmed a higher level of internal consistency in the proposed model. Hair et al. (2014) argued that indicator loadings must be statistically significant, and it need greater than of its standard threshold of o.80. therefore, the common method to establish convergent validity on a latent variable is Average Variance Extracted (AVE), and it has been defined as the grand mean value of squared loading of the indicators. A standard AVE threshold value of 0.50 or higher will explain more than half of the variance of the indicators in the model.

To explore the convergent validity of the mode, average variance extracted (AVE) are examined. It has been found that all the AVE values that are presented in Table 1, are greater than its threshold value of 0.50 , and this result has confirmed that convergent validity of the proposed model. The latent variable RA which has reported .370 , which is less than its threshold of 0.50 and indicated that it is not a valid factor in the model. However, Hair et al. (2014) argued that if composite reliability value is higher than 0.60 , then the convergent validity of the construct still adequate, and can be accepted. Therefore, RA construct will be in the model as an individual construct and will not be removed or incorporate with another.

As explained by Hair et al. (2014), Discriminant validity explains that a construct is truly distinct from other construct by empirical standards. There are two methods of accessing discriminant validity as (a). examining cross-loadings, and (b). using Fornell-Lacker criterion. Therefore, in this study, the FornellLacker criterion will be used to assess the discriminant validity. During the Fornell-Lacker process, it compares the square root of average variance extracted (AVE) with construct correlations.

Fornell and Larcker (1981) stated that the square root of AVE in each latent variable can be used to establish discriminant validity if this value is larger than other correlation values among the latent variables. Therefore, the results of the Fornell and Lacker's analysis that have been presented diagonally in Figure 6 have exceeded its standard threshold value of 0.50, which confirms the discriminant is well established in the model.

\begin{tabular}{lllllll}
\hline $\begin{array}{l}\text { Latent } \\
\text { Variable }\end{array}$ & AI & COM & CLX & PEOU & PU & RA \\
\hline AI & 0.690 & & & & & \\
COM & 0.440 & 0.710 & & & & \\
CLX & 0.260 & 0.290 & 1.00 & & & \\
PEOU & 0.400 & 0.500 & 0.370 & 0.840 & & \\
PU & 0.430 & 0.370 & 0.420 & 0.680 & 0.840 & \\
RA & 0.380 & 0.290 & 0.190 & 0.480 & 0.390 & 0.610
\end{tabular}

Figure 6: Values of coefficients determination $\left(R^{2}\right)$ 


\subsubsection{Approach 2 - Analysis of structural equation model}

Approach 1, the confirmatory factor analysis (CFA) has been designed to confirm the reliability and validity of the construct used in this study. Thus, approach 2, analysis of structural model is used to assess the results of the structural model, which will examine the model's predictive capabilities and the relationship between latent variables (construct).

Kock (2015) defined collinearity as a predictor-predictor phenomenon in multiple regression models. In this perspective, two or more predictors could measure the same underlining construct. Thus, path coefficients could be biased if the estimation involves significant level levels of collinearity among the predictor construct (Hair et al. 2014). Kock \& Lynn (2014) suggested that if all VIF's values are equal to or lower than 3.3, the model will be free of common method bias. Furthermore, Hair et al. (2014) has suggested that if collinearity is indicated by the tolerance, then researchers need to consider eliminating construct, merging predictors into a single constructor or creating a higher-order construct to treat collinearity issues.

As illustrated in Figure 1 and Figure 3, the structural model relationship represents the hypothesized relation between construct in the model. The path coefficients of the model illustrated have a standardized value between -1 and +1 . Therefore, estimated path coefficients close to +1 indicate a strong positive relationship that is always statistically significant. Furthermore, the estimated path coefficients closer to o indicate the weaker relationship, and statistically nonsignificant. However, Hair et al. (2014) argued that whether an estimated path coefficient is significant eventually depends on its standard error. Therefore, path coefficient is significant at a certain error probability, when t value is greater than the critical value. Hair et al. (2011) mentioned that commonly used critical values for two-tailed tests are 1.65 (significant level =10\%), 1.96 (significance level $=5 \%$ ), and 2.57 (significance level $=1 \%$ ). As mentioned by both [46] and [51], critical value 1.96 with significance level $=5 \%$ has been adopted in this study.

The coefficient of determination or R2 value measures the predictive accuracy, and calculate the squared correlation between endogenous construct's actual and predictive values of the proposed model of this study. Thus, the R2 value ranges from o to 1, where a higher level of R2 indicates the higher level of predictive accuracy of the construct in this model. Hair et al. (2014) suggested that scholarly research could use the $\mathrm{R} 2$ values ranging from $0.75,0.5$ and 0.25 . Therefore, the $\mathrm{R} 2$ value of 0.50 has been adopted as a moderate value in this study.

In addition to evaluate the R2 values of the endogenous construct in this study, it is an essential procedure to evaluate the change in R2 values when a specified exogenous construct is omitted from the model. Thus, f2 effect size will be used to examine whether omitted construct has a substantial impact on the endogenous constructs in the model.

In addition to evaluating the magnitude of R2 values of predictive accuracy, it is an important procedure to examine the Q2 value, which is an indicator of the model's predictive relevance. Hair et. al., (2011) mentioned that Q2 accurately predicts the data points of indicators in reflective measurement model of endogenous constructs and endogenous single item construct. Hair et al. (2011) further extended his argument and concluded that Q2 values greater than o for a reflective endogenous construct indicate the path model's predictive relevance of a construct.

To investigate the significance of inner-model and outer-models, T-statistic values are generated through the bootstrap procedure in SmartPLS. The means and standard errors of each coefficient were computed. The two-tailed statistics were used to determine if the mean value of each coefficient was significantly different from $\mathrm{o}$ at the conventional $\alpha=.50$ level of statistical significance (Balasooriya et al. 2017, Isma'ili et al. 2016) Table 2, the T-statistic values of $\mathrm{H}_{1}, \mathrm{H}_{3}, \mathrm{H} 4, \mathrm{H} 6, \mathrm{H} 8, \mathrm{H} 9, \mathrm{H} 10$ and $\mathrm{H} 12$ have exceeded the standard threshold value of 1.96. This result has confirmed the outer loading of the proposed model is highly significant, and the validity of the $\mathrm{H} 1, \mathrm{H} 3, \mathrm{H} 4, \mathrm{H} 6, \mathrm{H} 8, \mathrm{H} 9, \mathrm{H} 1 \mathrm{O}$ and $\mathrm{H} 12$. Therefore, we can confirm that the hypotheses $\left(\mathrm{H}_{1}, \mathrm{H}_{3}, \mathrm{H} 4, \mathrm{H} 6, \mathrm{H} 8, \mathrm{H} 9, \mathrm{H} 1 \mathrm{O}\right.$ and $\left.\mathrm{H} 12\right)$ that have been developed are true and they can be adopted. However, $\mathrm{H}_{2}, \mathrm{H}_{5}, \mathrm{H}_{7}$ and $\mathrm{H}_{11}$ are not highly significant in the proposed model, and thus, it cannot be adopted. 


\begin{tabular}{|l|c|c|c|c|c|c|}
\hline Paths & $\begin{array}{l}\text { Hyp } \\
\text { othe } \\
\text { sis }\end{array}$ & Original Sample (O) & Sample Mean (M) & Standard Error & T-Statistics & P-Value \\
\hline PEOU -> PU & H12 & 0.57 & 0.57 & 0.07 & 8.17 & 0 \\
\hline RA -> PEOU & H3 & 0.34 & 0.35 & 0.06 & 5.56 & 0 \\
\hline COM -> PEOU & H6 & 0.34 & 0.34 & 0.06 & 5.18 & 0 \\
\hline CLX -> PEOU & H9 & 0.21 & 0.19 & 0.06 & 3.68 & 0 \\
\hline COM -> AI & H4 & 0.3 & 0.29 & 0.09 & 3.29 & 0 \\
\hline CLX -> PU & H8 & 0.19 & 0.19 & 0.06 & 3.18 & 0 \\
\hline PU -> AI & H10 & 0.25 & 0.25 & 0.1 & 2.54 & 0.01 \\
\hline RA -> AI & H1 & 0.2 & 0.22 & 0.08 & 2.53 & 0.01 \\
\hline RA -> PU & H2 & 0.08 & 0.09 & 0.07 & 1.16 & 0.25 \\
\hline CLX -> AI & H7 & 0.04 & 0.04 & 0.06 & 0.65 & 0.52 \\
\hline PEOU -> AI & H11 & -0.04 & -0.04 & 0.1 & 0.41 & 0.68 \\
\hline COM -> PU & H5 & 0 & 0.01 & 0.06 & 0.07 & 0.94 \\
\hline
\end{tabular}

Table 2. Summary of T-value significance

\section{Significance of the study}

Based on the results of the two-tier approach used in this study, it has been revealed that hypothesized relation between PEOU and PU is highly significant, and PEOU significantly affects the PU (0.572). Also, it has been revealed that relationship between PEOU and AI is non-significant, and PEOU has a strong negative effect on $\mathrm{AI}(-0.040)$. furthermore, RA (0.344) and COM (o.335) will moderately impact PEOU but has a weaker impact on PU. In addition, it has been revealed that Compatibility (COM) has a strongest direct impact (0.344) on adoption Intention followed by Relative Advantage (0.202). Complexity (CLX) has indicated that it has the weakest direct influence (0.042) on adoption intention.

In addition to above findings, analysis of inner model demonstrated in Figure 4 expressed that Relative Advantage (RA), Compatibility (COM), Complexity (CLX) Previewed Ease of Use (PEOU) and Perceived Usefulness (PU) together can only explain $31 \%$ of the variance in adoption intention. Furthermore, Relative Advantage (RA), Compatibility (COM), Complexity (CLX) Perceived Ease of Use (PEOU) together have explained only $51 \%$ of the variance in Perceived Usefulness (PU), and together with Relative Advantage (RA), Compatibility (COM), Complexity (CLX) explained only $40 \%$ of the variance in Perceived Ease of Use(PEOU). However, despite uncaptured concerns in the inner model, Figure 4 suggests that Relative Advantage (RA), Compatibility (COM), Complexity (CLX) and Perceived Usefulness (PU) together is more significant in influencing adoption intention of new technologies, which is also not found in previous studies.

\section{Conclusion and future direction}

This paper has examined how organizations can improve Cloud adoption decisions by evaluating an integrated TOE and TAM frameworks. Thus, this paper has combined only technical component of the TOE with TAM framework and examined how those factors of the integrated framework could improve the adoption decisions. This study is empirically examined using 200 statistically valid samples, and results were validated for reliability and validity and confirmed the suitability of the hypotheses. The results of this analysis have provided the valuable insight and deeper understanding of the literature.

During the analysis, PLS-SEM technique has been used to analyse the data and it proved that the technique is fit for this type of research studies.

The scope of this research study was limited to an Australian organization and technology component of the TOE framework, and PU and PEOU of the TAM framework. As a future direction, the original scope of this study can be extended to other organizations and countries, and extend the scope of the TOE and TAM frameworks. 
With the increasing popularity of Cloud services, Cloud security and privacy issues are gaining their importance. While there are several Cloud security issues, the one that is most worrisome for customers is data security, which includes data confidentiality and privacy protection. Stringent security measures must be used to protect the Cloud data from hacker attacks. Hackers target user data with the intention of identity theft or financial fraud, which are very serious problems. Furthermore, Cloud service providers must consider using service level agreements to provide an assurance to their customers about data protection and privacy.

In this review, applicable data and privacy protection laws have been discussed briefly, which is an important factor in the adoption or use of this Cloud computing technology. Thus, this area must be explored in detail in future studies.

\section{References}

Abduljalil, K.M., and Zainuddin, Y. 2015. "Integrating technology acceptance model and motivational model towards intention to adopt accounting information system", International Journal of Management, Accounting \& Economics, vol. 2, no. 5, pp. 346-359.

Alijani, G.S., Fulk, H.K., Omar, A., and Tulsi , R. 2014. "Cloud computing effects on small business", Entrepreneurial Executive, vol. 19, pp. 35-45.

AlKharusi, M.H., and Al-Badi, A.H. 2016. "IT personnel perspective of the slow adoption of Cloud computing in public sector: Case study in Oman”, 2016 3rd MEC International Conference on Big Data \& Smart City (ICBDSC), pp. 1.

Anderson, J.C., Gerbing, D.W., and Masters, J.C. 1998. "Structural Equation Modeling in Practice: A Review and Recommended Two-Step Approach,” Psy. Bull., vol. 103, pp.411-423.

Armitage, C.J., and Conner, M. 2001. "Efficacy of the theory of planned behaviour: A meta-analytic review," Br. J. Soc. Psychol., vol. 40, pp. 471-499.

Ashraf, A.R., Narongsak, T., and Seigyoung, A. 2014 "The application of the technology acceptance model under different cultural contexts: The case of online shopping adoption", Journal of International Marketing, vol. 22, no. 3, pp. 68-93.

Awa, H.O., Ojiabo, O.U., and Emecheta, B.C. 2015. "Integrating TAM, TPB and TOE frameworks and expanding their characteristic constructs for e-commerce adoption by SMEs', J. Sci. Technol. Policy Manage., vol. 6, pp. 76-94.

Balasooriya, P., Wibowo, S., and Wells, M. 2016. "Green Cloud computing and economics of the Cloud: moving towards sustainable future,” Proc.7th Annual Int. Conf. ICT: Big Data, Cloud Security, Singapore.

Balasooriya, P., Wibowo, S., and Wells, M. 2017. "Factors influencing Cloud technology adoption in Australian organizations" . In: The 2nd International Conference on Information Technology, Nakhonpathom, Thailand.

FĂDor, A.G. 2014. "Innovation and technology acceptance model (TAM): A theoretical approach", Romanian Journal of Marketing, no. 2, pp. 59-65.

Fornell, C and Larcker, D.F. 1981."Evaluating structural equation models with unobservable variables and measurement error," Journal of marketing research, pp. 39-50.

Haimes, Y., Horowitz, B., Guo, Z., Andrijcic, E., and Bogdanor, J. 2015. "Assessing Systemic Risk to Cloud $\square$ Computing Technology as Complex Interconnected Systems of Systems". Systems Engineering, 18(3), pp. 284-299.

Hair, J.F., Sarstedt, M., Hopkins, L., and Kuppelwieser, V.G. 2014. "Partial least squares structural equation Modeling (PLS-SEM): an emerging tool in business research", European Business Review, 26, pp. 106-121.

Hair, J.F., Ringle, C.M., and Sarstedt, M. 2011. "PLS-SEM: Indeed a Silver Bullet", The Journal of Marketing Theory and Practice, 19(2), pp. 139-152.

Hameed, M.A., and Counsell, S. 2014. "Establishing relationships between innovation characteristics and it innovation adoption in organizations : a meta-analysis approach", International journal of innovation management, vol. 18, no. 1, pp. 1-41. 
Hsin-Pin, F., and Hsiang-Ting, S. 2014. "A framework for a technology-organization-environment implementation model in taiwan's traditional retail supermarkets", International Journal of Organizational Innovation, vol. 6, no. 3, pp. 121-129.

Hung, S.Y., Hung, W.H., Tsai, C.A., and Jiang, S.C. 2010. "Critical factors of hospital adoption on CRM system: Organizational and information system perspectives”, Decision Support Systems, vol. 48, pp. 592-603.

Isma'ili, A., Li, M.J., Shen, J., and He, Q. 2016. “Cloud computing adoption decision modelling for SMEs: a conjoint analysis" International Journal of Web and Grid Services, 12, pp. 296-327.

Kock, N. 2015. "Common method bias PLS-SEM: a full collinearity assessment approach", International Journal of e-Collaboration, vol.11.

Kock, N., and Gasking, L. 2014. "The mediating role of voice and accountability in the relationship between internet diffusion and government corruption in Latin America and Sub-Saharan Africa”, Information Technology for Development, 20(1), pp. 23-43.

Legris, P., Ingham, J., and Collerette, P. 2003. "Why do people use information technology? A critical review of the technology acceptance model”, Information \& Management, vol. 40, no. 3, pp. 191204.

Lin, H.F. 2014. "Understanding the determinants of electronic supply chain management system adoption: Using the technology-organization-environment framework", Technological Forecasting \& Social Change, vol. 86, pp. 80-92.

Maresova, P., Sobeslav, V., and Krejcar, O. 2017. "Cost-benefit analysis - evaluation model of Cloud computing deployment for use in companies". Applied Economics, 49(6), pp. 521-533.

Premkumar, G., Ramamurthy, K., and Nilakanta, S. 1994. "Implementation of electronic data interchange: An innovation diffusion perspective”, Journal of Management Information Systems, vol. 11, no. 2, pp. 157-186.

Ratten, V. 2015. "International consumer attitudes toward Cloud computing: A social cognitive theory and technology acceptance model perspective", Thunderbird International Business Review, vol. 57, no. 3, pp. 217-228.

Raza, M.H., Adenola, A.F., Nafarieh, A., and Robertson, W. 2015. "The slow adoption of Cloud computing and IT workforce", Procedia Computer Science, vol. 52, pp. 1114-1119.

Rogers, E.M. 2010. "Diffusion of innovations", Simon and Schuster.

Sintonen, S., and Immonen, M. 2013. "Telecare services for ageing people: Assessment of critical factors influencing the adoption intention," Comput. Hum. Behav., vol. 29, pp.1307-1317.

Tornatzky, L.G. 2005. "Innovation U: New practices, enabling cultures", Creating Knowledge, Strengthening Nations: The Changing Role of Higher Education.

Tsai, L., and Hsu, L. 2012. "A study of the institutional forces influencing the adoption intention of RFID by suppliers", Inform. Manage.

Völckner, F., Sattler, H., Hennig-Thurau, T., and Ringle, C.M. 2010. "The role of parent brand quality for service brand extension success". Journal of Services Research, 13, pp. 379-396.

Wang, Y.M., Wang, Y.S., and Yang, Y.F. 2010. "Understanding the determinants of RFID adoption in the manufacturing industry", Technological Forecasting \& Social Change, vol. 77, pp. 803-815.

Wang, Y.S., Li, H.T., Li, C.R., and Zhang, D.S. 2016. "Factors affecting hotels' adoption of mobile reservation systems: A technology-organization-environment framework", Tourism Management, vol. 53, pp. 163-172.

Willcocks, L.P., Venters, W., and Whitley, E.A. 2013. "Cloud sourcing and innovation: slow train coming?A composite research study”, Strategic Outsourcing (17538297), vol. 6, no. 2, pp. 184.

$\mathrm{Wu}, \mathrm{B}$. , and Chen, X. 2017. "Continuance intention to use MOOCs: Integrating the technology acceptance model (TAM) and task technology fit (TTF) model", Computers in Human Behavior, pp. 221. 
Copyright: (C) 2018 P. Balasooriya. This is an open-access article distributed under the terms of the Creative Commons Attribution-NonCommercial 3.0 Australia License, which permits non-commercial use, distribution, and reproduction in any medium, provided the original author and ACIS are credited. 